\title{
RETICULOCYTE PARAMETER ANALYSIS IN THE AUTOMATED HAEMATOLOGY ANALYZER USED IN THE LABORATORIES
}

\author{
MST SHAILA YESMIN ${ }^{1}$, TUHIN SULTANA ${ }^{2}$, CHANDAN KUMAR ROY ${ }^{3}$, MD QUDDUSUR RAHMAN ${ }^{2}$, AN \\ NASHIMUDDIN AHMED 4
}

\begin{abstract}
Background: Reticulocyte count with immature reticulocyte fraction (IRF) used in the laboratories to evaluate the bone marrow erythropoietic activity and have great diagnostic and prognostic importance in the treatment of anemias and other pathological conditions. Objective: The aim of this study was to establish the normal reference range for reticulocyte count and its parameter. Methods: In this study reticulocyte profile were evaluated by automated analysis in 40 healthy control subjects by XT-2000i (Sysmex) hematology analyzer and compared with measurements obtained by manual methods. Manually reticulocytes were supravitally stained with new methylene blue. Results: This study found MRC was $0.81 \pm 0.46 \%$.The FCMR was $0.97 \pm 0.17 \%$, Ret abs was found $.04 \pm .02\left(10^{6} /\right.$ $\mu l)$ and IRF was found $3.92 \pm 1.35 \%$. Conclusion: The precision of the automated analyzer was found significantly higher than the manual methods.
\end{abstract}

Keywords: Reticulocyte parameter, automated haematology analyzer.

\section{Introduction:}

Reticulocytes are the precursor red blood cells, 1015 micrometer in diameter 12,13 . They are cells, more rounded, non-nucleated and $20 \%$ greater, in volume, than the erythrocytes. Reticulocytes contain ribonucleic acid residues. These residues are stained with new methylene blue or brilliant cresyl blue dyes that confer the characteristic aspect of reticulum by brightfield microscopy. Known criteria were observed for good manual reticulocyte counting with special attention being paid to the preparation of reticulocyte slides, to counting fields without overlapping cells, and to the number of evaluated cells. The aim of this study was to evaluate the inter-observer variation and also to analyze the statistical error of manual reticulocyte counting. The reticulocytes can be classified as mature or immature depending on the amount of granules or reticula they contain. Reticulocyte counting is routinely and widely used in the laboratory to evaluate bone marrow erythropoietic activity. It is of great diagnostic and prognostic value in hemolytic anemias, in acute hemorrhage, in response to iron, folic acid and vitamin $B_{12}$ therapy, as well as, after chemotherapy or bone marrow transplantation $^{11}$. The manual method of reticulocyte counting is still very frequently used today due to its low cost in comparison to the automated method that has seen widespread. But the fully automated haematological analyzer has marked the most important progress in the last few years. These analyzers give the percentage and the absolute number of reticulocytes, together with new reticulocyte parameters that are much more accurate and precise than before. Moreover they give us a lot of information on the quality of reticulocytes and, therefore, on the recent erythropoiesis. The aim of this evaluation is to establish the reference range of reticulocyte parameters: Ret\%, Ret\#, IRF in the hematology analyzers.

\section{Materials and methods:}

This cross sectional study was carried out in the Clinical Pathology Department, BSMMU, Dhaka during the period of October' 2009 to September' 2010. Samples were taken from 40 healthy subjects, out of which 20 children and 20 adults were included in this study.

Automated reticulocyte counting was carried out in the haematology analyzer with reticulocyte counter in 40 healthy subjects. Blood sample $(2 \mathrm{ml})$ was collected in an EDTA tube for complete blood count $(\mathrm{CBC})$ and reticulocyte profile. Count was done

1. Assistant Professor, Dhaka Community Medical College

2. Associate Professor, Clinical pathology, Bangabandhu Sheik Mujib Medical University (BSMMU).

3. Assistant Professor, Clinical Pathology, BSMMU.

4. Professor, Clinical Pathology, BSMMU.

Bangladesh J Medicine 2010; 21 : 80-83 
preferrably within 2 hrs of collection. If delayed, blood sample was kept at 4ëë $\mathrm{C}$ before test. The measuring principle of the system is based on flow cytometry combined with hydrodynamic focusing. EDTA blood $(100 \mu \mathrm{l})$ is aspirated and intracellular RNA is stained by auramine $\mathrm{O}$, which is fluroscent under argon laser light ${ }^{\mathbf{1 2}}$. The reticulocyte population is further subdivided into LFR, MFR and HFR (Figure-II). The percentage of reticulocyte is given as the sum of LFR, MFR and HFR. The IRF was calculated by MFR plus HFR.

Manually supravital staining of unfixed RBCs was done with new methylene blue (NMB) in 40 healthy subjects. Then mixing of $100 \mu 1$ whole blood with 100 $\mu 1$ of $1 \%$ NMB solution in a $10 \times 75-\mathrm{mm}$ tube were done. After incubation at $37^{0}$ for $15-20$ minutes, the dilution was remixed and a wedge smear was performed $^{\mathbf{1 1}}$. The number of reticulocytes per 1000 RBCs was determined microscopically on x100 objective. Then percentage of reticulocyte was done. A reticulocyte was defined as a RBC containing at least 2 granules of reticulum (Figure-I). Absolute reticulocyte count was calculated from $\mathrm{RBC}$ count obtained from automated hematology analyzer.

All necessary and relevant data were processed. Data were evaluated by standard statistical methods. Analysis was done by SPSS (Statistical package for social science) by applying appropriate formula. Reference ranges were established by Mean, Median, Unpaired $t$ test and Co-efficient of variance test.

\section{Results:}

In this study randomly enrolled 40 healthy subjects were taken. Out of them 20 were children and 20 were adult. The healthy control children were divided into three age groups and healthy control adults were divided into four age groups. The maximum number $11(55.0 \%)$ was found in the age group of $6-10$ year followed by 5 (25.0\%) belonged to 1 - 5 year and 4 $(20.0 \%)$ belonged to $14-18$ year in healthy control children. In healthy control adults maximum number $9(45.0 \%)$ was found in the age group of $19-30$ year followed by 5 (25.0\%) belonged to 31 - 40 year, $4(20.0 \%)$ belonged to $41-50$ year and $2(10.0 \%)$ belonged to 51 60 year. It was found that $12(60.0 \%)$ of the healthy control children was male and $8(40.0 \%)$ was female. Male female ratio was $1.5: 1$. In healthy control adult male and female ratio was $1.9: 1$ and $13(65.0 \%)$ and $7(35.0 \%)$ were male and female respectively. The mean $( \pm \mathrm{SD}) \mathrm{MRC}$ was $0.77 \pm 0.46 \%$ and $0.85 \pm 0.46 \%$ in healthy children and healthy adults respectively. The mean coefficient of variance of MRC was $45 \%$ and $49 \%$ in healthy children and healthy adults respectively. The mean $( \pm \mathrm{SD})$ FCMR was $0.94 \pm 0.15 \%$ in healthy children and $1.0 \pm 0.19 \%$ healthy adults. The mean coefficient of variance of FCMR was $16 \%$ and $19 \%$ in healthy children and healthy adults respectively. The mean $( \pm \mathrm{SD})$ Ret abs was $0.04 \pm 0.03$ $\left(10^{6} / \mu 1\right)$ and $0.04 \pm 0.02\left(10^{6} / \mu 1\right)$ in healthy children and healthy adults respectively. The mean ( \pm SD) IRF was $3.92 \pm 1.69 \%$ in healthy children and $3.911 .0 \%$ healthy adults. No statistical significant difference $(p<0.05)$ was observed between healthy children and healthy adults.

Table-I

Comparison of MRC (\%), FCMR, Ret abs and IRF (\%) between healthy child and healthy adult $(n=40)$

\begin{tabular}{|c|c|c|c|}
\hline $\begin{array}{l}\text { Follow-up } \\
\text { (day) }\end{array}$ & $\begin{array}{c}\text { Control } \\
\text { (Children) } \\
(\mathrm{n}=20) \\
\mathrm{Mean} \pm \mathrm{SD}\end{array}$ & $\begin{array}{c}\text { Control } \\
\text { (Adult) } \\
(\mathrm{n}=20) \\
\text { Mean } \pm \text { SD }\end{array}$ & \\
\hline MRC (\%) & $0.77 \pm 0.46$ & $0.85 \pm 0.46$ & $0.611^{\mathrm{ns}}$ \\
\hline Range (min-max) & $(0.2-2)$ & $(0.2-2)$ & \\
\hline $\mathrm{CV}$ & 45 & 49 & \\
\hline FCMR (\%) & $0.94 \pm 0.15$ & $1.0 \pm 0.19$ & $0.752^{\mathrm{ns}}$ \\
\hline Range (min-max) & $(0.223-2)$ & $(0.26-2)$ & \\
\hline $\mathrm{CV}$ & 16 & 19 & \\
\hline Ret abs $(106 / \mu 1)$ & $0.04 \pm 0.03$ & $0.04 \pm 0.02$ & $0.564^{\mathrm{ns}}$ \\
\hline Range (min-max) & $(0.01-0)$ & $(0.01-0)$ & \\
\hline IRF (\%) & $3.92 \pm 1.69$ & $3.91 \pm 1.0$ & $0982^{\text {ns }}$ \\
\hline Range (min-max) & $(1.3-9)$ & $(2.1-6)$ & \\
\hline
\end{tabular}

$\mathrm{P}$ value reached from unpaired t-test

Table-II

Age distribution of the healthy control children and healthy control adult $(n=40)$

\begin{tabular}{lcccc}
\hline Age in year & $\begin{array}{c}\text { Control (Children) } \\
(\mathrm{n}=20)\end{array}$ & \multicolumn{2}{c}{$\begin{array}{c}\text { Control (Adult) } \\
(\mathrm{n}=20)\end{array}$} \\
& $\mathrm{N}$ & $\%$ & $\mathrm{n}$ & $\%$ \\
\hline $1-5$ & 5 & 25.0 & - & - \\
$6-10$ & 11 & 55.0 & - & - \\
$14-18$ & 4 & 20.0 & - & - \\
$19-30$ & - & - & 9 & 45.0 \\
$31-40$ & - & - & 5 & 25.0 \\
$41-50$ & - & - & 4 & 20.0 \\
$51-60$ & - & - & 2 & 10.0 \\
\hline
\end{tabular}




\section{Table-III}

Sex distribution of the healthy control children and healthy control adult of the studied subjects $(n=40)$

\begin{tabular}{lcccc}
\hline Sex & $\begin{array}{c}\text { Control (Children) } \\
(\mathrm{n}=20)\end{array}$ & \multicolumn{2}{c}{$\begin{array}{c}\text { Control (Adult) } \\
(\mathrm{n}=20)\end{array}$} \\
& $\mathrm{N}$ & $\%$ & $\mathrm{n}$ & $\%$ \\
\hline Male & 12 & 60.0 & 13 & 65.0 \\
Female & 8 & 40.0 & 7 & 35.0 \\
\hline
\end{tabular}

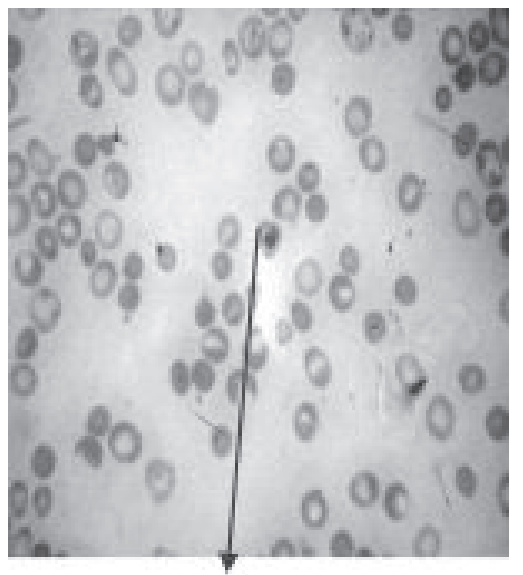

\section{Reticulocyte}

Fig-1: Photomicrograph of reticulocytes, Stained supravitally by new methylene blue (x1000).

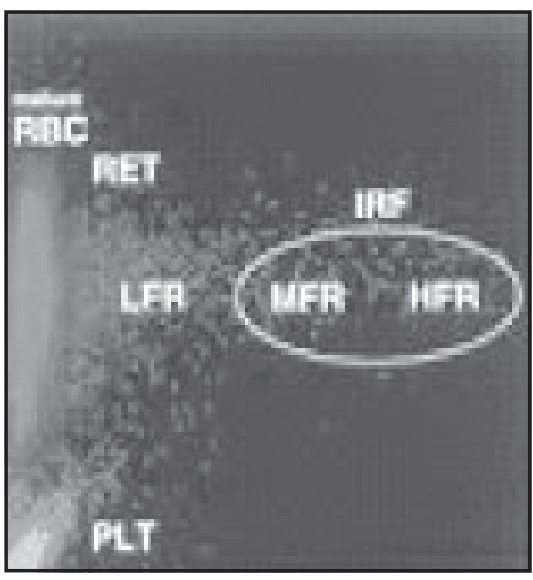

Fig-2: IRF scattergram in Sysmex XT-2000i in hematology analyzer.

\section{Discussions}

The traditional visual method of reticulocyte enumeration is limited in its usefulness because of the manual reticulocyte procedure's inherent imprecision. Coefficients of variation for the manual visual method are reported to range between $25 \%$ to greater than $50 \%{ }^{1}$. This study found $\mathrm{CV}$ of manual count was $47 \%$ and $\mathrm{CV}$ of automated analyzer was $17.5 \%$. Flow cytometric reticulocyte procedures use fluorescent dyes that bind to nucleic acids. Most clinical laboratory testing is performed using thiazole orange or auramine 0 . Possible disadvantages of these methods include high cost, time-consuming preparation, and the need for experienced or highly technical operators. Additionally some dyes are suspected carcinogens ${ }^{2}$. Most recently, reticulocyte analysis has been incorporated into hematology analyzers. All flow cytometric procedures increase the usefulness and versatility of reticulocyte analysis by improving precision ${ }^{2}$. Some procedures also provide information about reticulocyte subpopulations. Precision improves significantly with flow cytometric methods because an average of 30,000 to 50,000 cells is evaluated as compared to 1000 cells by the visual methods ${ }^{3}$.

Sandberg and collaborators established reticulocyte parameters by sysmex R-1000 and the technicon $\mathrm{H}^{*} 3$ as follows: Mean values: Reticulocytes $0.044 \times 10^{12} /$ L, IRF- $11.9 \%$, CV was 33\%. They did not identify any sex-associated difference in the reticulocyte count 4. This study found MRC was $0.81 \pm 0.46 \%$. The FCMR was $0.97 \pm 0.17 \%$, Ret abs was found $.04 \pm .02\left(10^{6} / \mu 1\right)$ and IRF was found 3.92 \pm 1.35 . Our study also did not found any sex related difference. Herkner evaluated automated reticulocyte enumeration in infants and children and established age dependent reference ranges ${ }^{7}$. Turowski and coworkers reported as mean \pm $2 \mathrm{SD}$ reticulocyte count $2.00 \pm 1.56 \%$; Absolute reticuocyte count $88.8 \pm 68.94 \times 10^{3} / \mathrm{ml}$ and $\mathrm{IRF}$ $0.22 \pm 0.16^{8}$. Reticulocyte quantification as a percentage or absolute count with immature reticulocyte fraction tests are simple, quick, inexpensive, reproducible and fairly reliable ${ }^{5,6}$. So, this study was done to establish the reference ranges for reticulocyte profile.

\section{References:}

1. Tanke H. 'Flow cytometry of human reticulocytes based on RNA fluorescence', Cytometry:1980; 313320.

2. Hoewen B. 'Reticulocyte maturation', Blood cells1992; 18:167-186.

3. Davis BH. 'Immature reticulocyte fraction (IFR): by any name, a useful clinical parameter of erythropoietic activity', Lab Hematol1996; 2:2-8.

4. Sandberg S, Rustad P, Johannesen B, Stolsnes B. 'Within subjects biological variations of reticulocytes and reticulocyte-derived parameters', Eur $J$ Haematol1998; 61: 42-48.

5. Tarallo P, Humbert JC, Mahassen $P$ et al. 'Retculocytes: reference limits', Clin Lab Haematol 1996; 18(1):13-14. 
6. Tarallo P, Humbert JC, Mahassen P. 'Reticulocytes: biological variations and reference limits', Eur $J$ Haematol1994, 53: 11-15.

7. Herkner KR. 'Clinical applications of reticulocyte maturity grading in paediatrics: an overview', Clin Lab Haem1994; 18 (Suppl. 1): 55-59.

8. Turowski D, Wysocka J, Butkiewicz AM. 'Peripheral blood reticulocytes and their reference range values for percentage, absolute count, and immature fraction in children, measured with flow cytometry', Folia Histochem Cytobiol2000; 38:31-6.

9. Bain BJ, Lewis SM, Bates I, 2008, 'Basic haematological techniques', In: Lewis SM, Bain BJ, Bates I, Dacie and Lewis Practical Haematology, $10^{\text {th }}$ eds. Philadelphia: Churchill living stone, pp.25-57.
10. Imazu M. 'General Description of the Automated Hematology Analyzer, XT-2000i', Sysmex J Int2002; 12: $13-17$.

11. Chang CC, Kass L. 'Clinical significance of immature reticulocyte fraction determined by automated reticulocyte counting, Am J Clin Pathol1997; 108: 69-73.

12. Davis BH, Bigelow NC, Koepke JA et al. 'Flow cytometric reticulocyte analysis. Multiinstitutional interlaboratory correlation study', Am $J$ Clin Patho 1994; 102: 468-477.

13. Riley S, Jonathon M, Ezra B,Goel R, Tidwell A. 'Reticulocytes and Reticulocyte Enumeration', Journal of Clinical Laboratory Analysis2001; 15:267-294. 